\title{
Prevalence of diabetes mellitus and impaired glucose regulation in Spain: the Di@bet.es Study
}

\author{
F. Soriguer • A. Goday • A. Bosch-Comas • E. Bordiú • A. Calle-Pascual • \\ R. Carmena • R. Casamitjana $\cdot$ L. Castaño • C. Castell • M. Catalá • E. Delgado • \\ J. Franch • S. Gaztambide • J. Girbés • R. Gomis • G. Gutiérrez • A. López-Alba • \\ M. T. Martínez-Larrad $\cdot$ E. Menéndez $\cdot$ I. Mora-Peces $\cdot$ E. Ortega $\cdot$ \\ G. Pascual-Manich • G. Rojo-Martínez • M. Serrano-Rios • S. Valdés • J. A. Vázquez • \\ J. Vendrell
}

Received: 21 July 2011 /Accepted: 19 September 2011 / Published online: 11 October 2011

(C) The Author(s) 2011. This article is published with open access at Springerlink.com

\begin{abstract}
Aims/hypothesis The Di@bet.es Study is the first national study in Spain to examine the prevalence of diabetes and impaired glucose regulation.
\end{abstract}

F. Soriguer $\cdot$ A. Bosch-Comas $\cdot$ R. Carmena $\cdot$ R. Casamitjana $\cdot$

L. Castaño $\cdot$ M. Catalá $\cdot$ S. Gaztambide $\cdot$ R. Gomis $\cdot$

G. Gutiérrez $\cdot$ M. T. Martínez-Larrad • E. Ortega •

G. Pascual-Manich · G. Rojo-Martínez $\cdot$ M. Serrano-Rios $\cdot$

$\mathrm{S}$. Valdés $\cdot \mathrm{J}$. Vendrell

Centro de Investigación Biomédica en Red de Diabetes y

Enfermedades Metabólicas Asociadas (CIBERDEM), Spain

URL: www.ciberdem.org

F. Soriguer $(\bowtie) \cdot G$. Rojo-Martínez $\cdot S$. Valdés

Department of Endocrinology and Nutrition,

Hospital Universitario Carlos Haya, Plaza del Hospital Civil, 29009 Malaga, Spain

e-mail: federico.soriguer.sspa@juntadeandalucia.es

\section{A. Goday}

Department of Endocrinology and Nutrition, Hospital del Mar,

Barcelona, Spain

A. Bosch-Comas · R. Gomis $\cdot$ E. Ortega

Institut d'Investigacions Biomèdiques August Pi i Sunyer

(IDIBAPS),

Barcelona, Spain

E. Bordiú

Laboratorio de Endocrinología,

Hospital Universitario S. Carlos de Madrid,

Madrid, Spain

\section{A. Calle-Pascual}

Department of Endocrinology and Nutrition,

Hospital Universitario S. Carlos de Madrid,

Madrid, Spain
Methods A population-based, cross-sectional, cluster sampling study was carried out, with target population being the entire Spanish population. Five thousand and seventy-two participants in 100 clusters (health centres or the equivalent

R. Carmena $\cdot$ M. Catalá

Department of Medicine and Endocrinology,

Hospital Clínico Universitario de Valencia,

Valencia, Spain

R. Casamitjana

Biomedic Diagnostic Centre University Hospital Clínic de

Barcelona,

Barcelona, Spain

L. Castaño $\cdot$ S. Gaztambide $\cdot$ G. Gutiérrez

Diabetes Research Group, Hospital Universitario de Cruces, UPV-EHU,

Baracaldo, Spain

C. Castell

Public Health Division, Department of Health,

Autonomous Government of Catalonia,

Barcelona, Spain

E. Delgado $\cdot$ E. Menéndez

Department of Endocrinology and Nutrition,

Hospital Central de Asturias,

Oviedo, Spain

J. Franch

EAP Raval Sud, Institut Català de la Salut, Red GEDAPS, Primary Care,

Unitat de Suport a la Recerca (IDIAP-Fundació Jordi Gol), Barcelona, Spain 
in each region) were randomly selected with a probability proportional to population size. Participation rate was $55.8 \%$. Study variables were a clinical and demographic structured survey, lifestyle survey, physical examination (weight, height, BMI, waist and hip circumference, blood pressure) and OGTT (75 g).

Results Almost $30 \%$ of the study population had some carbohydrate disturbance. The overall prevalence of diabetes mellitus adjusted for age and sex was $13.8 \%$ (95\% CI $12.8,14.7 \%$ ), of which about half had unknown diabetes: $6.0 \%(95 \%$ CI $5.4,6.7 \%)$. The age- and sex-adjusted prevalence rates of isolated impaired fasting glucose (IFG), isolated impaired glucose tolerance (IGT) and combined IFG-IGT were $3.4 \%$ (95\% CI 2.9, 4.0\%), 9.2\% (95\% CI $8.2,10.2 \%)$ and $2.2 \%$ (95\% CI $1.7,2.7 \%)$, respectively. The prevalence of diabetes and impaired glucose regulation increased significantly with age $(p<0.0001)$, and was higher in men than in women $(p<0.001)$.

Conclusions/interpretation The Di@bet.es Study shows, for the first time, the prevalence rates of diabetes and impaired glucose regulation in a representative sample of the Spanish population.

Keywords Epidemiology $\cdot$ Prevalence $\cdot$ Spain $\cdot$ Type 2 diabetes mellitus

J. Girbés

Diabetes Unit, Hospital Arnau de Vilanova,

Valencia, Spain

R. Gomis • E. Ortega

Endocrinology and Diabetes Unit, Hospital Clínic de Barcelona,

Universitat de Barcelona (UB),

Barcelona, Spain

A. López-Alba

Spanish Diabetes Society,

Madrid, Spain

M. T. Martínez-Larrad • M. Serrano-Rios

Lipids and Diabetes Laboratory,

Hospital Universitario S. Carlos de Madrid,

Madrid, Spain

I. Mora-Peces

Emergency Service, Hospital Nuestra Señora de los Reyes,

Valverde, Tenerife, Spain

J. A. Vázquez

Diabetes National Plan, Ministry of Health,

Madrid, Spain

J. Vendrell

Department of Endocrinology and Nutrition, Hospital

Universitario Joan XXIII,

Institut d'Investigacions Sanitaries Pere Virgili,

Tarragona, Spain

\section{Abbreviations}

$\begin{array}{ll}\text { FPG } & \text { Fasting plasma glucose } \\ \text { IFG } & \text { Impaired fasting glucose } \\ \text { IGR } & \text { Impaired glucose regulation } \\ \text { IGT } & \text { Impaired glucose tolerance } \\ \text { KDM } & \text { Known diabetes mellitus } \\ \text { UKDM } & \text { Unknown diabetes mellitus }\end{array}$

\section{Introduction}

Quantifying the number of people with diabetes is important because it allows for planning and rational judgement of resources. In Europe the prevalence of diabetes varies between studies [1]. The reasons for this are multiple, and include the different methodologies employed. Notably, only two national studies exist (Iceland and Portugal) [2]. Despite the importance for the design of strategies for diabetes, the data available on the prevalence of diabetes in different countries are limited.

In Spain, numerous studies have attempted to establish the prevalence of diabetes at different levels [3]. Most have shown prevalence rates of diabetes between $10 \%$ and $15 \%$, indicating that the established estimates have probably been surpassed [3].

We undertook, for the first time in Spain, a representative study of the prevalence of diabetes and IGR for the whole country, and evaluated its association with various risk factors

\section{Methods}

Population The Di@bet.es Study was a national, crosssectional, population-based survey conducted in 2009-10. A cluster sampling design was used to select participants, forming a representative random sample of the Spanish population. Of the eligible adults, $55.8 \%$ attended for examination, of whom 9.9\% were excluded by protocol (institutionalised, severe disease, pregnancy or recent delivery), giving a final sample of 5,072 individuals aged $\geq 18$ years $(41.6 \%$ men and $58.4 \%$ women). Of these, 1,952 (38.5\%) did not receive an OGTT: 481 with previously diagnosed diabetes, 87 with fasting capillary glycaemia $>7.8 \mathrm{mmol} / \mathrm{l}$, and 1,384 who refused the OGTT. The study was approved by the Ethics and Clinical Investigation Committee of Carlos Haya Hospital, and written informed consent was obtained from all participants.

Variables and procedures The participants were invited to attend a single examination visit at their health centre. Information was collected using a structured, intervieweradministered questionnaire, followed by a physical examina- 
tion. Fieldwork was undertaken by seven teams, each comprising a nurse and dietitian. After the interview, a fasting blood sample was obtained and a standard OGTT performed.

Age, sex, education level, smoking, level of daily physical activity (at work), leisure time sports and family history of diabetes (first and/or second degree relatives) were recorded.

Weight, height and waist and hip circumferences were measured by standardised methods. The BMI and WHR were calculated. Blood pressure was measured using a blood pressure monitor (Hem-703 C, Omron, Barcelona, Spain) after several minutes in a seated position; the mean of two measurements taken 1-2 min apart was used for analysis.

Subjects with baseline capillary blood glucose levels lower than $7.8 \mathrm{mmol} / \mathrm{l}$ and not receiving treatment for diabetes underwent a standard OGTT, obtaining fasting and $2 \mathrm{~h}$ venous samples. Samples were immediately centrifuged and serum was frozen until analysis. Serum glucose, triacylglycerols and cholesterol were measured enzymatically, and HDLcholesterol by a direct method. LDL-cholesterol was estimated by the Friedewald formula. Diabetes was diagnosed and classified according to the 1999 WHO criteria [4].

Statistical analysis The global prevalence was adjusted for the age and sex structure of the Spanish population. Not all the participants agreed to undergo the OGTT, and the prevalence of unknown diabetes mellitus (UKDM) was therefore calculated as: (number of diagnosed OGTT cases/ number of participants who underwent the OGTT $) \times(1-$ known diabetes mellitus [KDM] prevalence). The prevalence of IGR was calculated similarly [5].
Participants who accepted the OGTT were 2 years older than those who did not (49.2 vs 47.0 years, $p<0.001$ ), but there were no significant differences in sex or BMI between the two groups.

Associations between diabetes mellitus-IGR phenotypes and various risk factors were tested by logistic regression analyses, controlling for age, sex and BMI. Reported $p$ values are based on two-sided tests with statistical significance set at 0.05 .

\section{Results}

Almost $30 \%$ of the study population had some glucose disturbance. The total prevalence $(95 \% \mathrm{CI})$ of diabetes mellitus adjusted for age and sex was $13.8 \%(12.8,14.7 \%)$. Of these, almost half did not know they had the disease $(6.0 \%[5.4,6.7 \%])$. Isolated IFG was present in $3.4 \%(2.9$, $4.0 \%)$ and isolated IGT in $9.2 \%(8.2,10.2 \%)$. The prevalence of participants with combined IFG-IGT was $2.2 \%(1.7,2.2 \%)$. The prevalence of diabetes mellitus and IGR increased significantly with age $(p<0.0001)$, and was greater in men than women $(p<0.001)$ (Table 1).

The prevalence of obesity, abdominal obesity and hypertension was significantly higher in all diabetes-IGR phenotypes (Table 2). The probability of having raised triacylglycerol or low HDL-cholesterol levels was significantly higher in participants with KDM and UKDM, but the probability of having raised LDL-cholesterol was lower in

Table 1 Prevalence of diabetes and impaired glucose regulation according to sex and age

\begin{tabular}{|c|c|c|c|c|c|}
\hline \multirow[t]{2}{*}{ Variable } & \multicolumn{5}{|l|}{ Age (years) } \\
\hline & $18-30$ & $31-45$ & $46-60$ & $61-75$ & $>76$ \\
\hline \multicolumn{6}{|l|}{ Men } \\
\hline$n$ & 306 & 603 & 578 & 494 & 193 \\
\hline Isolated IFG & $0.32(-0.31,0.96)$ & $2.32(1.11,3.52)$ & $6.74(4.70,8.79)$ & $4.85(2.96,6.75)$ & $6.21(2.81,9.62)$ \\
\hline Isolated IGT & $2.84(0.59,5.09)$ & $6.28(3.91,8.64)$ & $10.8(7.58,14.1)$ & $12.9(9.02,16.8)$ & $16.9(10.1,23.7)$ \\
\hline Combined IFG-IGT & $0.47(-0.45,1.40)$ & $2.41(0.92,3.91)$ & $1.51(0.23,2.79)$ & $4.22(1.88,6.56)$ & $3.38(0.10,6.66)$ \\
\hline UKDM & 0.0 & $4.53(2.87,6.20)$ & $11.9(9.34,14.6)$ & $17.6(14.2,21.0)$ & $16.7(11.4,22.0)$ \\
\hline KDM & $0.32(-0.31,0.96)$ & $2.15(0.99,3.31)$ & $11.9(9.29,14.5)$ & $24.8(21.0,28.7)$ & $20.7(15.0,26.4)$ \\
\hline \multicolumn{6}{|l|}{ Women } \\
\hline$n$ & 369 & 853 & 818 & 608 & 250 \\
\hline Isolated IFG & $0.81(-0.1,1.72)$ & $1.99(1.05,2.93)$ & $5.74(4.15,7.34)$ & $5.09(3.35,6.84)$ & $4.00(1.57,6.42)$ \\
\hline Isolated IGT & $3.89(1.52,6.26)$ & $3.95(2.28,5.62)$ & $6.99(4.83,9.15)$ & $10.9(7.82,14.0)$ & $20.2(13.5,26.9)$ \\
\hline Combined IFG-IGT & $0.38(-0.37,1.15)$ & $1.31(0.34,2.29)$ & $1.74(0.63,2.86)$ & $2.73(1.10,4.36)$ & $6.01(2.07,9.95)$ \\
\hline UKDM & $0.31(-0.2,0.87)$ & $1.28(0.53,2.04)$ & $4.32(2.93,5.71)$ & $11.1(8.60,13.6)$ & $18.1(13.3,22.9)$ \\
\hline KDM & $0.27(-0.25,0.80)$ & $0.93(0.29,1.58)$ & $6.60(4.89,8.30)$ & $18.7(15.6,21.8)$ & $23.2(17.9,28.4)$ \\
\hline
\end{tabular}

Data are $\%(95 \% \mathrm{CI})$ 
participants with KDM than in any other group. A low education level was more frequent in participants with KDM.

The probability of smoking, doing exercise in their free time at least once weekly and the intensity of work activity did not differ significantly between the different metabolic phenotypes (Table 2).

The prevalence of a family history of diabetes (first and/ or second degree relative) was greater in all diabetes-IGR phenotypes (Table 2).

Finally, the multivariate logistic regression analysis showed that the presence of diabetes mellitus was significantly associated with age (OR [95\% CI] $1.05[1.04,1.06])$, sex (less frequent in women [OR $0.34(0.28,0.45)])$, education level (greater risk in persons without education [OR 1.28 $(1.02,1.62)])$, obesity (OR $1.70[1.37,2.05])$, abdominal obesity (OR $2.20[1.75,2.76])$, high blood pressure (OR 2.26 [1.77, 2.87]), low HDL-cholesterol (OR 1.54 [1.25, 1.91]), high triacylglycerols (OR $1.99[1.60,2.48])$ and a family history of diabetes (OR 2.70 [2.21, 3.31]).

\section{Discussion}

The present study, using a representative sample of the whole national population, shows that the prevalence of diabetes mellitus in Spain is $13.8 \%$, with $6.8 \%$ having UKDM discovered during the study fieldwork.

A total of 13 studies from nine European countries (three from Spain) were included in the Decode Study, involving 7,680 men and 9,251 women aged 30-89 years. The

Table 2 Association between diabetes and impaired glucose regulation categories and various risk factors

\begin{tabular}{|c|c|c|c|c|c|c|c|c|}
\hline \multicolumn{2}{|l|}{ Variable } & $\begin{array}{l}\text { Normal } \\
\text { OGTT }\end{array}$ & IFG & IGT & $\mathrm{IFG}+\mathrm{IGT}$ & UKDM & KDM & $p$ value \\
\hline \multicolumn{2}{|l|}{$n$} & 3,760 & 198 & 309 & 80 & 244 & 481 & \\
\hline \multicolumn{2}{|l|}{ Age (years) } & $46.3 \pm 16.0$ & $57.6 \pm 12.6$ & $59.7 \pm 16.1$ & $60.1 \pm 15.9$ & $62.8 \pm 13.7$ & $65.6 \pm 11.5$ & $<0.0001^{\mathrm{a}}$ \\
\hline \multirow[t]{2}{*}{ Obesity (BMI $\geq 30 \mathrm{~kg} / \mathrm{m}^{2}$ ) } & $\%$ & 23.2 & 51.2 & 48.2 & 53.8 & 60.2 & 50.2 & $<0.0001^{\mathrm{b}}$ \\
\hline & OR $(95 \% \mathrm{CI})$ & 1 & $2.8(1.9,4.1)$ & $2.5(1.9,3.2)$ & $3.4(2.1,5.5)$ & $4.2(3.1,5.5)$ & $2.4(2.0,3.1)$ & \\
\hline \multirow{2}{*}{$\begin{array}{l}\text { Abdominal obesity (WHR } \\
>1 \text { in men or WHR }>0.85 \\
\text { in women) }\end{array}$} & $\%$ & 33.1 & 52.7 & 57.9 & 70.5 & 65.1 & 68.1 & $<0.0001^{\mathrm{b}}$ \\
\hline & OR $(95 \% \mathrm{CI})$ & 1 & $2.2(1.4,3.4)$ & $2.2(1.6,2.9)$ & $4.3(2.4,7.7)$ & $3.8(2.7,5.3)$ & $3.5(2.7,4.5)$ & \\
\hline \multirow{2}{*}{$\begin{array}{l}\text { Hypertension } \\
\text { (antihypertensive } \\
\text { treatment or a systolic BP } \\
\geq 140 \mathrm{mmHg} \text { and } / \text { or } \\
\text { diastolic } \mathrm{BP} \geq 90 \mathrm{mmHg} \text { ) }\end{array}$} & $\%$ & 34.3 & 67.8 & 69.5 & 77.2 & 79.1 & 83.3 & $<0.0001^{\mathrm{c}}$ \\
\hline & OR $(95 \% \mathrm{CI})$ & 1 & $1.9(1.2,2.9)$ & $1.7(1.2,2.3)$ & $2.5(1.3,4.6)$ & $2.2(1.5,3.3)$ & $2.5(1.9,3.4)$ & \\
\hline \multirow{2}{*}{$\begin{array}{l}\text { High LDL-cholesterol }(\geq 3.9 \\
\mathrm{mmol} / \mathrm{l})\end{array}$} & $\%$ & 6.6 & 9.5 & 8.3 & 11.1 & 8.8 & 4.4 & $0.07^{\mathrm{d}}$ \\
\hline & OR $(95 \% \mathrm{CI})$ & 1 & $1.3(0.7,2.06)$ & $0.9(0.6,1.4)$ & $1.3(0.6,2.8)$ & $0.8(0.6,1.4)$ & $0.4(0.2,0.7)$ & \\
\hline \multirow{2}{*}{$\begin{array}{l}\text { High triacylglycerols } \\
\qquad(\geq 1.7 \mathrm{mmol} / \mathrm{l})\end{array}$} & $\%$ & 15.4 & 29.6 & 34.2 & 36.1 & 45.6 & 39.4 & $<0.0001^{\mathrm{c}}$ \\
\hline & OR $(95 \% \mathrm{CI})$ & 1 & $1.4(0.9,2.3)$ & $2.0(1.5,2.6)$ & $1.9(1.1,3.2)$ & $3.0(2.2,4.0)$ & $2.4(1.9,3.1)$ & \\
\hline \multirow{2}{*}{$\begin{array}{l}\text { Low HDL-cholesterol }(<1.0 \\
\mathrm{mmol} / 1 \text { in men or } 1.3 \\
\mathrm{mmol} / \mathrm{l} \text { in women })\end{array}$} & $\%$ & 29.1 & 38.6 & 34.2 & 34.7 & 39.4 & 48.4 & $<0.0001^{\mathrm{c}}$ \\
\hline & OR $(95 \% \mathrm{CI})$ & 1 & $1.3(0.6,1.5)$ & $1.2(0.9,1.6)$ & $1.1(0.6,1.8)$ & $1.5(1.1,2.0)$ & $2.4(1.8,2.9)$ & \\
\hline \multirow{2}{*}{$\begin{array}{l}\text { Low education level (no } \\
\text { education or only primary } \\
\text { studies) }\end{array}$} & $\%$ & 8.5 & 19.2 & 21.6 & 27.5 & 25.8 & 31.5 & $0.03^{\mathrm{c}}$ \\
\hline & OR $(95 \% \mathrm{CI})$ & 1 & $1.29(0.86,1.95)$ & $1.24(0.88,1.72)$ & $1.74(0.98,3.07)$ & $1.38(0.98,1.95)$ & $1.66(1.29,2.14)$ & \\
\hline \multirow{2}{*}{$\begin{array}{l}\text { Smokers (more than one } \\
\text { cigarette/day) }\end{array}$} & $\%$ & 28.4 & 25.2 & 15.7 & 23.2 & 29.9 & 15.8 & $0.19^{\mathrm{c}}$ \\
\hline & OR $(95 \% \mathrm{CI})$ & 1 & $1.34(0.86,2.09)$ & $0.72(0.51,1.02)$ & $1.21(0.67,2.18)$ & $1.16(0.82,1.66)$ & $0.90(0.68,1.19)$ & \\
\hline \multirow[t]{2}{*}{ Have an active job style } & $\%$ & 14.1 & 16.5 & 8.9 & 10.0 & 9.1 & 8.2 & $0.06^{\mathrm{c}}$ \\
\hline & OR $(95 \% \mathrm{CI})$ & 1 & $1.46(0.87,2.44)$ & $0.70(0.45,1.08)$ & $0.80(0.36,1.78)$ & $0.71(0.44,1.16)$ & $0.67(0.47,0.97)$ & \\
\hline \multirow{2}{*}{$\begin{array}{l}\text { Do leisure exercise at least } \\
\text { once a week }\end{array}$} & $\%$ & 39.8 & 33.9 & 32.5 & 32.9 & 35.9 & 30.2 & $0.09^{\mathrm{c}}$ \\
\hline & OR $(95 \% \mathrm{CI})$ & 1 & $0.91(0.61,1.37)$ & $0.80(0.61,1.05)$ & $0.88(0.52,1.49)$ & $0.96(0.71,1.30)$ & $0.72(0.57,0.90)$ & \\
\hline \multirow{2}{*}{$\begin{array}{l}\text { Family history of diabetes } \\
\text { mellitus (first and/or } \\
\text { second degree relative) }\end{array}$} & $\%$ & 47.1 & 53.3 & 45.2 & 46.8 & 49.6 & 62.7 & $<0.0001^{\mathrm{c}}$ \\
\hline & OR $(95 \% \mathrm{CI})$ & 1 & $1.70(1.14,2.53)$ & $1.38(1.06,1.80)$ & $1.37(0.33,2.28)$ & $1.67(1.24,2.26)$ & $3.47(2.76,4.36)$ & \\
\hline
\end{tabular}

OR were obtained by logistic regression models adjusted for sex, age and BMI where indicated

${ }^{\text {a }}$ Adjusted for sex

${ }^{\mathrm{b}}$ Adjusted for age and sex

${ }^{\mathrm{c}}$ Adjusted for age, sex and BMI

d Adjusted for age, sex, BMI and statin therapy 
conclusion reached was that in the majority of European countries the prevalence of diabetes and IGR is moderate or low $(<10 \%$ in people younger than 60 and $10-20 \%$ in people aged $60-80$ years) [5].

Other studies on diabetes mellitus prevalence have been undertaken in other European countries with data obtained from case records or from structured interviews, but with no OGTT. In other cases, local studies are extrapolated to the total national territory, and this may or may not represent the prevalence over the whole country. There may also exist important differences between countries in the prevalence of obesity, physical activity or eating patterns, which might partially explain the variation in diabetes prevalence [6].

In a recent Portuguese study using the same methodology as ours, the total prevalence of diabetes mellitus was $11.7 \%$, very similar to that for the Spanish population [2]. In both studies diabetes mellitus prevalence was significantly higher in men than women. In our study, the prevalence of KDM was somewhat greater and UKDM somewhat less than that published in earlier studies in Spain [3] and Portugal [2]. The prevalence of IFG and IGT was also lower than that found in earlier Spanish studies [3] or recently in Portugal [2], where the prevalence of IFG and IGT was $23 \%$. Different health strategies, different methodologies or a different prevalence of obesity or other metabolic risk factors might explain these differences in contemporary studies in which the overall diabetes mellitus prevalence was very similar.

In our study, diabetes mellitus and IGR were significantly associated with a greater frequency of obesity, high blood pressure, hypertriacylglycerolaemia and low HDLcholesterol as expected [7]. However, people with KDM probably receive statin therapy more frequently, which may explain the lower level of LDL-cholesterol in people with KDM.

Finally, people with a low educational level had a $28 \%$ increased risk of having diabetes mellitus after adjustment for other risk factors closely associated with diabetes. A lower socioeconomic level has been associated with a poorer state of health, higher rates of mortality and cardiovascular diseases, and an increase in diabetes prevalence [8].

The main strengths of this study are first, the sampling was representative of the whole national territory, and second, the diagnosis of diabetes was made by OGTT in the majority of cases. The study, however, has a few limitations: the participation was relatively low (56\%) and there was a greater participation of women and older people, meaning all the prevalence and analysis data were corrected for age and sex. In addition, not all the participants underwent the OGTT, but the prevalence of diabetes mellitus and IGR was calculated taking this into account, as indicated in the Methods section. Although, for clinical purposes, an OGTT needs to be reassessed to establish diagnostic status, it is widely accepted that one OGTT is enough in the setting of epidemiological studies. Another limitation is that the information was selfreported, although this, too, is common practice in large epidemiological surveys.

In summary, this study contributes information for the first time on the prevalence of diabetes mellitus and IGR in Spain. The results will provide our public health authorities with data that should encourage the urgent implementation of clinical and preventive intervention programmes to tackle the increasing health and economic burden of diabetes in Spain.

Acknowledgements We thank P. Zimmet for critically reading the manuscript and making several useful remarks. We wish to acknowledge the kind collaboration of the following entities: the Spanish Diabetes Society, the Spanish Diabetes Federation and the Ministry of Health Quality Agency. Our profound appreciation goes to the primary care managers and personnel of the participating health centres, as well as to L. Forga and F. Casanueva for their inestimable help in the management of the Northern zone. To all the fieldworkers, nurses and dietitians, (I. Alonso, A. Arocas, R. Badia, C.M. Bixquert, N. Brito, D. Chaves, A. Cobo, L. Esquius, I Guillén, E. Mañas, A.M. Megido, N. Ojeda, R.M. Suarep, M.D. Zomeño), without whose work the study would not have been possible to carry out and to all the people who voluntarily participated in the study. Financing: supported by CIBER in Diabetes and Associated Metabolic Disorders-CIBERDEM (ISCIII-Ministerio de Ciencia e Innovación), Ministerio de Sanidad y Consumo and Spanish Society of Diabetes-SED. LifeScan España (Madrid, Spain) kindly donated the glucometers and test strips for capillary glucose measurements.

Contribution statement All the authors contributed to the interpretation of data, discussion of results and critical review, and gave final approval of the version to be published.

Duality of interest The authors declare that there is no duality of interest associated with this manuscript.

Open Access This article is distributed under the terms of the Creative Commons Attribution Noncommercial License which permits any noncommercial use, distribution, and reproduction in any medium, provided the original author(s) and source are credited.

\section{References}

1. Shaw JE, Sicree RA, Zimmet PZ (2010) Global estimates of the prevalence of diabetes for 2010 and 2030. Diabetes Res Clin Pract $87: 4-14$

2. Gardete-Correia L, Boavida JM, Raposo JF et al (2011) First diabetes prevalence study in Portugal: PREVADIAB study. Diabet Med 27:879-881 
3. Valdes S, Rojo-Martinez G, Soriguer F (2007) Evolution of prevalence of type 2 diabetes in adult Spanish population. Med Clin (Barc) 129:352-355

4. Alberti KG, Zimmet PZ (1998) Definition, diagnosis and classification of diabetes mellitus and its complications. Part 1: diagnosis and classification of diabetes mellitus provisional report of a WHO consultation. Diabet Med 15:539-553

5. DECODE-Study-Group (2003) Age- and sex-specific prevalences of diabetes and impaired glucose regulation in 13 European cohorts. Diabetes Care 26:61-69
6. Varo JJ, Martinez-Gonzalez MA, de Irala-Estevez J, Kearney J, Gibney M, Martinez JA (2003) Distribution and determinants of sedentary lifestyles in the European Union. Int $\mathrm{J}$ Epidemiol 32:138-146

7. Saely CH, Aczel S, Koch L et al (2010) Diabetes as a coronary artery disease risk equivalent: before a change of paradigm? Eur J Cardiovasc Prev Rehabil 17:94-99

8. Guize L, Jaffiol C, Gueniot M et al (2008) Diabetes and socioeconomic deprivation. A study in a large French population. Bull Acad Natl Med 192:1707-1723 